\title{
Civil Aviation Occurrences in Indonesia
}

\author{
Agus Pramono $\mathbb{D}^{1,2}{ }^{1,2}$ Jason H Middleton, ${ }^{1}$ and Carlo Caponecchia ${ }^{1}$ \\ ${ }^{1}$ School of Aviation, UNSW Sydney NSW, Kensington, Australia \\ ${ }^{2}$ Legal Service, Indonesia Air Force, Jakarta, Indonesia \\ Correspondence should be addressed to Agus Pramono; a.pramono@student.unsw.edu.au
}

Received 16 November 2019; Revised 17 March 2020; Accepted 6 May 2020; Published 29 May 2020

Academic Editor: Kyriakos Kourousis

Copyright (C) 2020 Agus Pramono et al. This is an open access article distributed under the Creative Commons Attribution License, which permits unrestricted use, distribution, and reproduction in any medium, provided the original work is properly cited.

Globally, civil air traffic has been growing rapidly in recent years, and with this growth, there has been a considerable improvement in air safety. However, in Indonesia, the recent rate of incidents and accidents in aviation is far higher than the global average. This study aims to assess civil aviation safety occurrences in Indonesia and, for the first time, to investigate factors contributing to these occurrences within commercial Indonesian aviation operations. In this study, 97 incident/accident investigation reports published by the Indonesian National Transportation Safety Committee between 2007 and 2015 were analysed. The most common occurrences involved Runway Excursions, Loss of Control In-Flight, and Controlled Flight into Terrain. In terms of the likelihoods of the occurrences and the severity of consequences, Runway Excursions were more common while Loss of Control In-Flight and Controlled Flight into Terrain events were more severe and often involved fatalities. In Indonesia, Runway Excursions were usually nonfatal and comprised $45 \%$ of the occurrences for commercial flights, compared to $34 \%$ globally. Further, in this study, weather and Crew Resource Management issues were found to be common contributing factors to the occurrences. Weather was a contributing factor for almost $50 \%$ of the occurrences involving Indonesian commercial flights. Adverse weather contributed to Loss of Visual Reference for visual flight operations in mountainous areas, which contributed to the majority of Indonesian fatal accidents. The combination of Indonesian monsoon climate and mountainous weather characteristics appears to provide many risks, mitigation of which may require specialist pilot training, particularly for multicrew aircraft. In identifying the main contributing factors, this study will hopefully provide motivation for changes in training and operations to enhance future aviation safety in Indonesia.

\section{Introduction}

Globally, civil aviation has been marked by two general trends: increasing traffic volume and an improving safety record. The International Civil Aviation Organisation (ICAO) notes that air traffic internationally has increased by $78 \%$ in the last two decades, from 18 million aircraft departures in 1995 to 32 million in 2014 [1,2], and to 34 million departures in 2015 [3]. Concurrently, global safety statistics are improving [4]. The International Civil Aviation Organisation (ICAO) notes that the accident rate of commercial aviation has dramatically decreased from 4.8 per million departures in 2008 to 2.78 million in 2015 [5, 6].

Indonesian domestic civil aviation traffic is also growing rapidly. Scheduled commercial air traffic has grown from 377,632 departures (or 0.37 million departures) in 2008 to
729,448 departures (or 0.73 million departures) in 2015 $[7,8]$. Concurrently, the Indonesian rate of accidents has declined from 13.92 per million departures in 2008 to 6.06 per million departures in 2015 [9].

While there is a declining accident rate in line with the global trend, the Indonesian accident rate is still considerably higher than the average global rate [10]. The Chief of the IATA Accident Classification Task Force (ACTF) also noted that Indonesia's accident rate has been and still is an area of concern $[11,12]$. This was highlighted in the public eye in October 2018 and February 2019 by accidents which involved the same operator, Lion Air [13, 14]. The earlier accident resulted in 189 fatalities, while the later was a nonfatal overrun incident. The fatal accident occurred over the Java Sea during climb, while the other was at Pontianak airport during landing. Aircraft design failure was a major 
contributing factor for the fatal, while the overrun occurred in heavy rain $[13,14]$.

In contrast to most other States where safety records and contributing factors have been comprehensively analysed and discussed in the literature, the Indonesian record has not been evaluated in any substantive form. Previous studies that have discussed Indonesian Aviation safety performance were limited to specific aspects, ranging from the strategic to operational levels, such as financial-related issues, airport infrastructure policy, aircraft maintenance, and the level of pilots' adherence to standard operating procedures (SOPs) that contributed to the incidents [10, 15-17]. Earlier work describing safety in the least well developed countries [15], includes Indonesian airport operations [16], poor aviation maintenance [10], and safety being viewed from a regulatory perspective [17], as well as cultural factors that might contribute to the Indonesian accident rate [18]. The latter article suggested that cultural factors play an important role in aviation safety and should be incorporated into investigation reports; however, the study does not elaborate on the ways in which cultural factors might contribute to Indonesian aviation safety. In addition, none of these papers discuss factors that may contribute to the Indonesian rate of accidents such as weather, terrain, runway surface conditions, and unstable approaches. By contrast, more detailed studies have been undertaken on factors that contribute to incidents for other countries including India [19], Canada [20], the USA, Australia, New Zealand, and Norway [21]. Therefore, it is instructive to consult with incident/accident investigation reports which comprise considerable useful pieces of information that enable us to reconstruct and to learn from the incidents [22-24].

The uniqueness of Indonesia's terrain and weather is of interest since these factors may be associated with accidents. Indonesia is an archipelagic country situated along the equator and surrounded by oceans with high sea surface temperatures, which drive a tropical monsoon climate that creates precipitation of more than $4,000 \mathrm{~mm}$ per year in some places during the wet season which often lasts for more than 250 days per year [25]. Embedded in a monsoon climate, orographic weather which is often found in mountainous areas can also degrade visibility for pilots who are flying visually. Hays [26] stated that in mountainous areas, weather is highly unpredictable because of atmospheric processes by which heavily moisture laden air turns into cloud and rainfall, commonly occurring in valleys or saddle point gaps between mountains.

According to the National Transportation Safety Committee from 2010 to 2016, incidents/accidents were distributed across most major islands of Indonesia but were concentrated in Papua ( 25 accidents, 35 serious incidents) and Java (20 accidents and 35 serious incidents) followed by Sumatera (10 accidents and 18 serious incidents) [27] (KNKT (in Bahasa Komisi Nasional Keselamatan Transportasi) or NTSC (National Transport Safety Committee) uses definitions of accident and incident from the ICAO Annex 13 as stated in KNKT website). Java has many major airports located in flatter topography with jet services, while the Papua highlands have many poorly developed airstrips served by smaller turbo-propeller powered aircraft [27].

Indonesian civil aviation is dominated by domestic flight services rather than international services. Most of the domestic flights are served by Indonesian operators, operating as Full Service Carriers (FSC) or Low Cost Carriers (LCC). Since deregulation began in 2000, the number of air operators has grown. Indonesian commercial flights fall within ICAO Operational Classification Part 121 for scheduled flights and Part 135 for unscheduled flights. Both of these types of commercial flights serve major airports. General Aviation (GA) flights, governed by Part 91 for private or charter and Part 137 for aerial work are most common in remote and mountainous where airports are less well developed, navigational facilities are rare, and weather is often poor and rapidly changing. Despite the fact that the weather Visual Flight Rules (VFR) are the only possible option for many sectors in mountainous areas, Instrument Flight Rules (IFR) cannot be used without the required navigation aids, and GNSS (Global Navigation Satellite System) approaches have not been developed for many of the smaller regional airports.

Cloud, rain, and wind are important elements of weather-related incidents and are associated with the tropical monsoon climate. According to the Indonesian Meteorology Bureau (BMKG), average annual rainfall for Indonesia during wet seasons is over $3,000 \mathrm{~mm}$ and is a result of the large scale air circulation of the Indian and the Pacific Oceans [25]. The Indonesian wet season usually spans from October to April, while the dry season spans from May to August and is much influenced by the Australian desert climate. The complexity of mainland Asia and Australian continental weather, coupled with local topographical terrain, are contributors to irregular weather patterns. In addition, the large topographical variations across Indonesia, varying from lowland coastal areas to the highland interior, also make winds difficult to predict [26].

Due to the higher rate of incidents when compared to global figures and a lack of previous evaluation of safety records, this study aims to analyse the nature of commercial aviation safety occurrences in Indonesia, and their contributing factors.

\section{Methods}

In choosing the methodology for this study, the authors noted that there are no previous studies at all which have attempted to describe the nature of civil aviation accidents in Indonesia, or to ascertain which are the important factors which contribute to those accidents. The Indonesian government, as a signatory to ICAO, has established the air accident investigation bureau and placed this agency under the National Transportation Safety Committee (NTSC) which oversees the safety of all modes of transport. The air investigation bureau has a requirement to analyse all fatal and major accidents and to report in accordance with ICAO Annex 13. Investigating authorities will often be left with incomplete records and incomplete or inaccurate personal 
accounts and have to use their professional judgments to assess contributing factors.

Therefore, it was decided to firstly analyse all such reports in a given period in order to determine in a descriptive fashion what types of accidents occurred, and where. The second phase of this study concerns analysing which contributing factors are associated with these events. We have chosen to list all contributing factors but not attempted to identify those that are most important. While we understand that human factors are probably associated with some accidents, and that weather may play a role since Indonesia has a long and intensive wet season, we have simply chosen to list the contributing factors, noting that there may be several for each accident, and determine a list of those factors which are most common, whether contributing alone or in association with others. In this way the list of contributing factors has been determined by those listed in the reports themselves, not prejudged by the authors of this paper. We believe this an objective methodology and the analysis is at a level of interpretation equal to that of the reports which are the foundations of this analysis.

2.1. Data. The data used in this analysis were derived from NTSC incident/accident investigation reports, which present the accidents and serious incidents that occurred in Indonesian territory between 2007 and 2015. The reports are maintained by NTSC and available in the NTSC website (http://knkt.dephub.go.id/knkt/ntsc_aviation/aaic.htm).

NTSC air investigators were sent to accident/incident sites to conduct investigations and summarize findings. The incident/accident investigation reports provide details on the nature of accidents and serious incidents and contributing factors. All publicly available incident/accident investigation reports maintained by NTSC from 2007 to 2015 were accessed for use in this study [14].

2.2. Research Procedures. The reports were downloaded between January and March 2016. Next, information from the reports was extracted on the basis of flight features: occurrence categories and contributing factors. In order to extract this information, the most salient sections of the investigation reports were inspected closely, these being the introduction, the conclusion, and safety recommendations. The lead author extracted information about these features of each incident, which was later verified by another author. The ICAO Aviation Occurrence Categories (AOC) [28] and the ACTF of IATA [29] were used to analyse the investigation reports. Definitions of these categories are provided below.

Flight features refer to flight registration (country of registration: Indonesian or foreign-registered); flight carriage (passenger or cargo); flight functions (commercial, private; training or agriculture); flight weight (measured in MTOW: large aircraft having MTOW $>5,700 \mathrm{~kg}$ and small aircraft with MTOW <5,700 kg); and engine type (jets or turboprops).
Occurrence categories refer to the nature of either an accident or an incident.

These include the following:

(i) Controlled Flight into Terrain (CFIT): when an airworthy aircraft under complete control of flight crew is unintentionally flown into terrain, water, or obstacles.

(ii) Loss of Control In-flight (LOC-I): an extreme manifestation of a deviation from the intended flight path.

(iii) Runway Excursion (RE): a single aircraft that inappropriately exited from the runway: landing long/overrun and lateral Runway Excursion, including landing short.

(iv) Abnormal Runway Contact (ARC): any landing or take-off involving abnormal runway or landing surface contact, such as heavy landing and gear-up landing as well as tail strike.

(v) System/Component Failure or Malfunction (SCF): failure or malfunction of an aircraft system or component related to the power plant, or other systems.

(vi) Runway Incursion-Animal (RI-A): collision with, risk of collision, or evasive action taken by an aircraft to avoid an animal on a runway or on a helipad/helideck in use.

(vii) Runway Incursion-Vehicle, Aircraft, or Person (RI-VAP): any occurrence at an aerodrome involving the incorrect presence of an aircraft, vehicle, or person on the protected area of a surface designated for the landing and take-off of aircraft.

(viii) Cabin safety Events (CABIN): miscellaneous occurrences in the passenger cabin of transport category aircraft.

(ix) Fire/Smoke (Nonimpact) (F-NI): fire or smoke in or on the aircraft, in-flight, or on the ground, which is not the result of impact.

"Contributing factors" are defined as actions, omissions, events, conditions, or a combination thereof, which, if eliminated, avoided, or absent, would have reduced the probability of the accident or incident occurring, or mitigated the severity of the consequences of the accident or incident. The identification of contributing factors does not imply the assignment of fault or the determination of administrative, civil, or criminal liability [30]. In terms of the contributing factors to this analysis, it should be noted that official NTSC reports list contributing factors, but not in coded form. Therefore, the authors of this analysis needed to assign contributing factors based on the written listings provided by the NTSC. The coarse discrimination between factors as defined in this paper facilitated common agreement between the present authors. For example, any communication failures between pilots or pilots and ATC were defined solely as CRM issues. Similarly, any deviation 
at all from SOPs which were relevant to the accident was designated as deviation from SOPs without further discrimination. Even if there were several SOP deviations during the one flight, the contributing factors "SOP" were only listed once.

In Indonesia, aircraft incident investigations conducted by the NTSC have specific guidelines [31]. During the investigation process, the NTSC may form a number of investigator groups, one of which is an operations and aircraft performance group. This group deals with the information pertaining to the operation of the aircraft prior to and during the occurrence. The group focuses on the information flow to pilots from all sources and then uses that information to understand pilot decisions and actions. The group examines many aspects, including flight planning, flight profile, crew experience, air traffic services, and communications made among crew [31]. The group coordinates with other investigator groups, including a data recorder group which is responsible for providing relevant data obtained from Flight Data Recorder (FDR) and Cockpit Voice Recorder (CVR). The findings of the operation and aircraft performance group are then shared and verified by other parties involved on a consultation basis before the factual information is finalised. Other concerned parties include specialists, accredited representatives, and advisers participating in the investigation. The purpose of the consultation is to ensure that the gathered information is complete and accurate.

\section{Results}

Between 2007 and 2015, there were 128 accidents or serious incidents that were reported by the NTSC: 123 Indonesian-registered aircraft and five foreign-registered aircraft. The latter were excluded from analysis due to the objectives of the study. A further 26 General Aviation (GA) incidents were also excluded from our present analysis. This section presents the incident-based analysis of the 97 remaining reports which relate to commercial aviation occurrences, with a particular focus on the 84 with multiple contributing factors. Runway Excursion was the most frequent occurrence, and Crew Resource Management (CRM) was shown to be the most frequent contributing factor, followed by weather (WX) and Unstable Approaches (USAPP).

This section presents a descriptive analysis of the categories of the incidents/accidents. Figure 1 shows the distribution of incident/accident investigation reports across Commercial and GA and is divided into various subcategories of fixed wing and rotary wing aircraft, and large and small aircraft.

3.1. Flight Features. As shown in Figure 1, commercial flights were the most common $(n=97)$ of the total 123 incidents/accidents reported amongst the categories of aircraft. Of these 89 commercial flights, 80 were passenger flights, 12 were cargo, and three were a combination of passenger and cargo flights. Of the commercial flights, 48 were large jet-engine aircraft, while 41 were turbopropdriven aircraft, which were comprised of 18 large aircraft and 23 small aircraft. In addition, there were eight helicopters involved, comprising 7 passenger flights and one cargo.

3.2. Incident/Accident Categories. As shown in Figure 2, Runway Excursions were the most common category (44), featuring in 42 occurrences during the landing phase, comprising 11 overruns, 27 runway veer-offs, and four undershoots. There were only two excursions during takeoff.

Figure 2 also shows that all overrun events involved jetdriven aircraft while more than two-thirds of the veer-offs involved turboprops. Undershoots involved the same number of jet-driven aircraft as turboprops, while the two take-off-related occurrences were turboprops. Although Runway Excursions were the most common occurrence, they contributed little to fatalities. Of the 44 excursions, only two were fatal and both happened during landings (one overrun and one undershoot/landing short), and together resulted in 45 fatalities.

Figure 2 shows that the 13 LOC-I and 12 CFIT events each comprised 11 fatal incidents (22 of the total 24 fatal incidents) accounting for 411 fatalities. Despite that, Figure 2 also depicts other events, leading to nonfatality. They are three particular nonfatal events: Abnormal Runway Contact, Runway Incursion (RI), and wrong-runway landings and all involve multiple contributing factors.

The remaining 84 of the 97 occurrences were caused by multiple contributing factors, including weather (WX), CRM, Runway Conditions (RW) and technical malfunction (TECH). These occurrences include the 24 flights on which fatalities were experienced. Flights with fatalities were most common on Papua Island, followed by Kalimantan, Sulawesi and Sumatera, Java, and then Nusa Tenggara. The 13 singlefactor incidents comprise 11 with System Component Failures (SCF), one with a Cabin Safety Event and one Fire/ Smoke (nonimpact) event. These are also excluded from the following discussion as they were only caused by a single (technical) factor as coded in the NTSC reports, leading to an unknown incident/accident category.

Table 1 highlights that incidents/accidents were most common in Papua, followed by Java and Sumatera, and then Kalimantan and Sulawesi with the remaining four large islands contributing with a further 10 occurrences. The Runway Excursion events were most common in Papua, followed by Java and Sumatera, and then Sulawesi and the remaining four islands had eight Runway Excursion events. The LOC-I and CFIT events were most common in Papua, followed by Kalimantan, and then Sulawesi and Sumatera. The ARC/RI/wrong-runway landings mostly occurred in Java, followed by Sumatera, and then Papua and the remaining four islands combined with four. In addition, Table 1 shows the distribution of aircraft categories across the islands. Papua involved more turboprops, followed by Kalimantan and Sulawesi while jet incidents/accidents were more common in Java and Sumatera. 


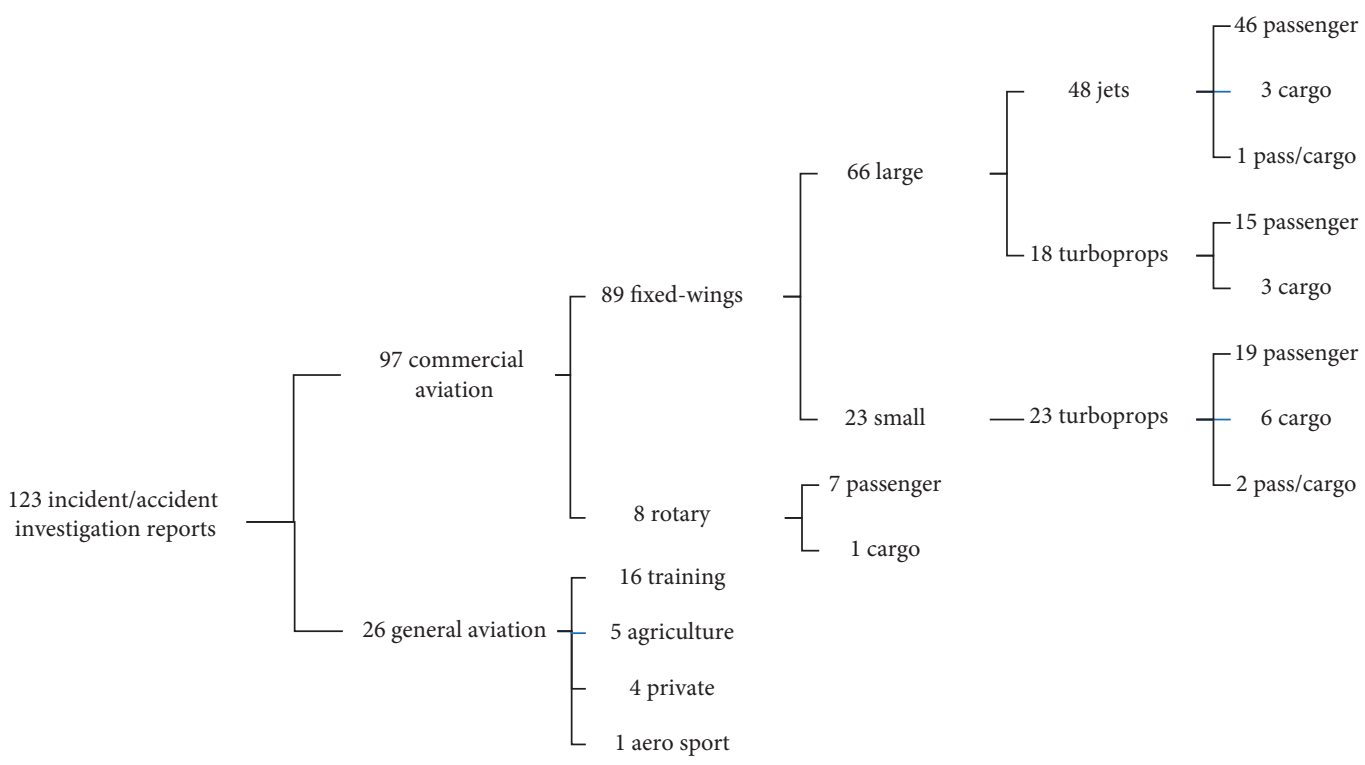

FIGURE 1: Categories of aircraft involved in the 123 incident/accident investigation reports from 2007 to 2015 (note that General Aviation occurrences were not further considered in the current analysis).

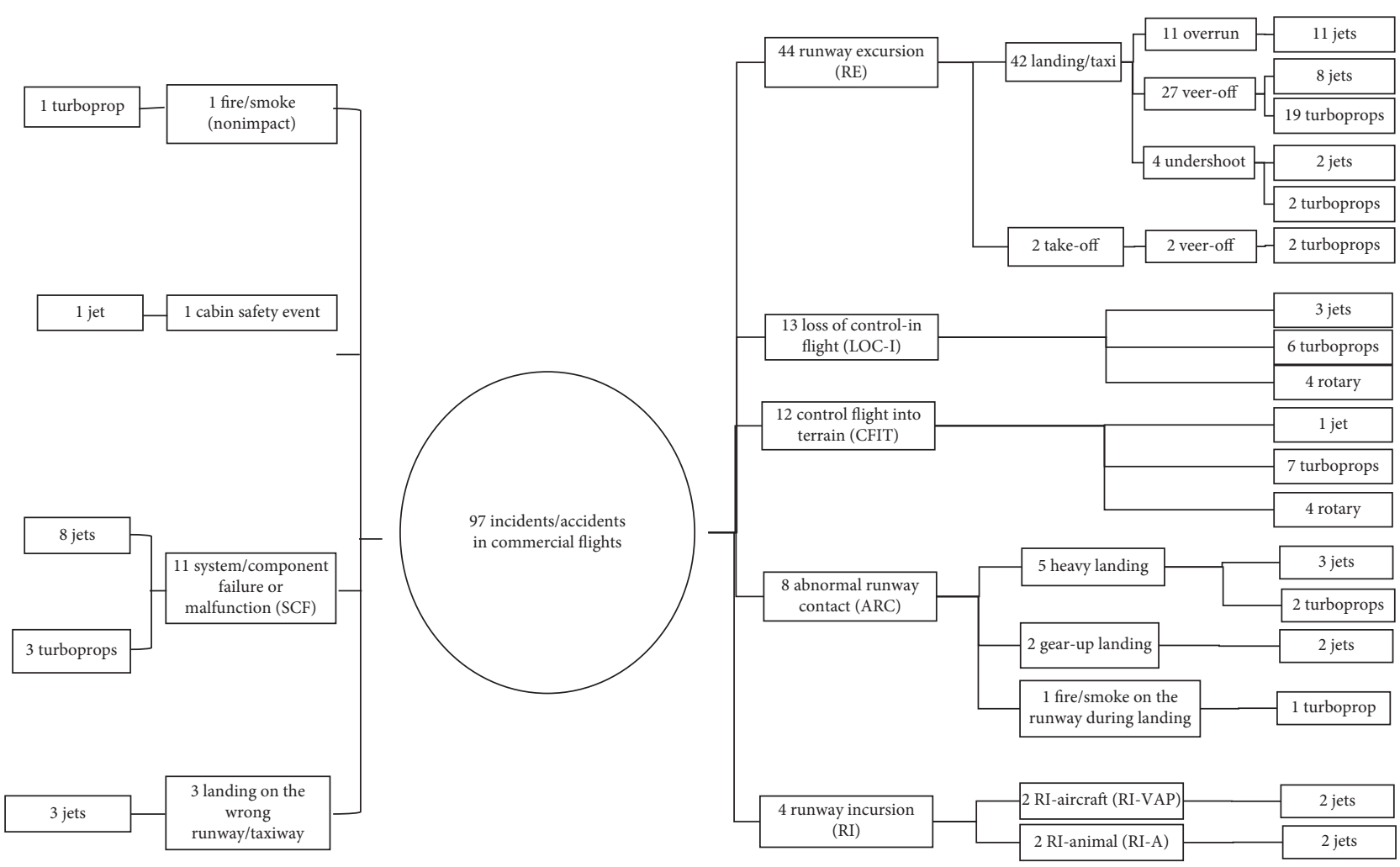

FIgURE 2: Incident/accident categories involving commercial flights in Indonesia occurring between 2007 and 2015.

3.3. Contributing Factors. This section describes factors nominated in the incident reports which, both alone and in combination, contributed to the incidents. Poor CRM (pilot leadership, teamwork, decision-making communication between pilots, or pilots and Air Traffic Control, etc.) was the most common factor contributing to incidents/accidents on commercial flights (74\%), followed by weather (58\%) and USAPP
(Unstable Approaches) (45\%), and then Runway Conditions (30\%) and technical failures (19\%). In terms of the 24 fatal occurrences, CRM contributed to the most (96\%), followed by weather (63\%) and technical (21\%), and then Runway Conditions and USAPP (8\%). Technical failures, while playing a role, are only mentioned in 16 reports, while CRM issues were by far the most prevalent, contributing to 62 incidents. 


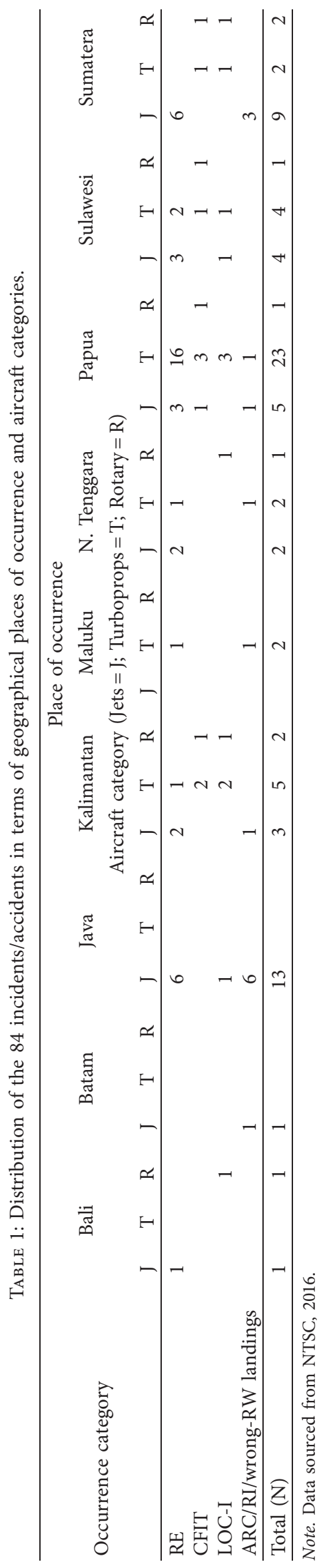




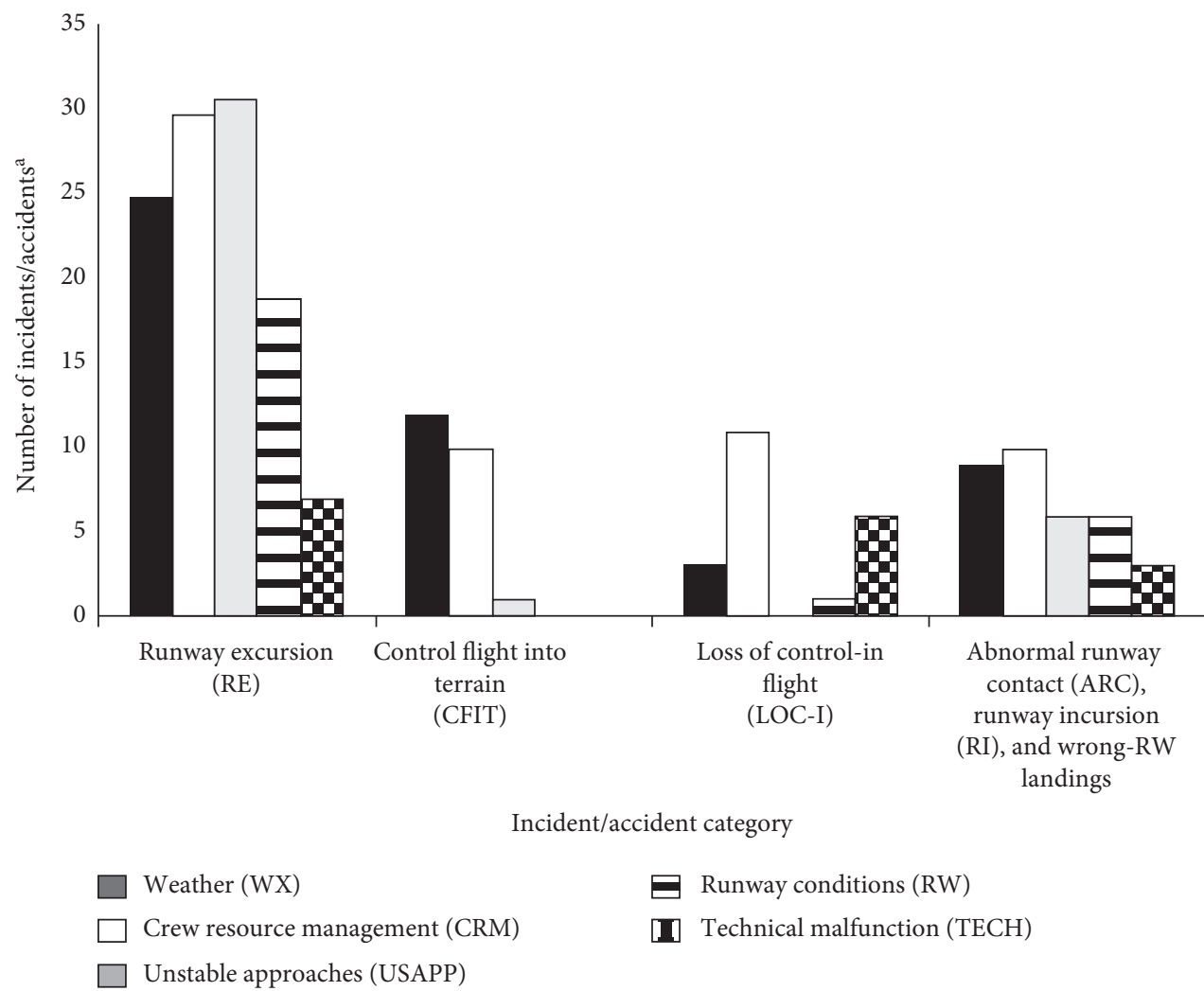

FIGURE 3: Distribution of contributing factors to the RE; LOC-I and CFIT and ARC, RI, and wrong-runway landings incidents/accidents on the 84 commercial flights. ${ }^{a}$ Note that more than one contributing factor was possible for each occurrence.

Figure 3 demonstrates that CRM communication breakdowns and weather were factors which were present across all types of occurrences. More specifically, for the Runway Excursion occurrences technical malfunction was the least common factor while USAPP was important. In the CFIT events, weather was the most common factor, followed by CRM, with USAPP the least common. In the LOC-I, CRM issues were the most prevalent, followed by technical issues and weather. In the ARC, RI, and wrong-runway landings events, CRM breakdowns were most common, followed by weather, USAPP, and Runway Conditions while technical factors were least common.

The Runway Excursion and Abnormal Runway Contacts, RI, and wrong-runway landing occurrences mostly occurred during the wet season, which spans the period from October to March [32]. The Runway Excursion events mostly occurred in December while the Abnormal Runway Contacts, RI, and wrong-runway landing events occurred in November. By contrast, the LOC-I and CFIT occurrences mostly happened outside the rainy season, reaching their peak in the months of April and August. But we note that cloud and weather changes involving cloud are common through any season in the highlands.

3.4. Runway Excursions (RE). Runway Excursions, where aircraft ran off the end or the side of the runway or taxiway, were a major component of incidents/accidents, accounting for 44 of the 84 occurrences. To understand if there were common contributing factors across incidents, the five main contributing factors (WX, TECH, CRM, USAPP, RW) were examined. While this is a very broad classification, this approach permits a straightforward first-order analysis and understanding of the key features. Reports for each incident/ accident were analysed to determine which factors played a role. From Figure 4, it is evident that technical malfunction, while playing a role, were only mentioned in seven reports, while unstable approach issues were by far the most prevalent. CRM issues, weather, and Runway Conditions also contributed highly to the Runway Excursion incidents/ accidents.

In terms of multiple factors (Figure 5), the pair of CRMUSAPP had the highest prevalence. The triplet of weatherCRM-USAPP had the highest prevalence, while the four-factor combination of WX-CRM-USAPP-RW was the largest in that respective category. The combination of weather-CRM-USAPP issues in 19 Runway Excursion occurrences involved more jets than turboprops and, with the exception of two cargo accidents, all 19 were passenger aircraft. According to the NTSC reports, the contributing factors were mostly a lack of the compliance of the flight crew to the SOPs, inadequate training for pilots, the inability of air traffic controllers to relay current weather information, and a lack of current information on runway surface conditions. 


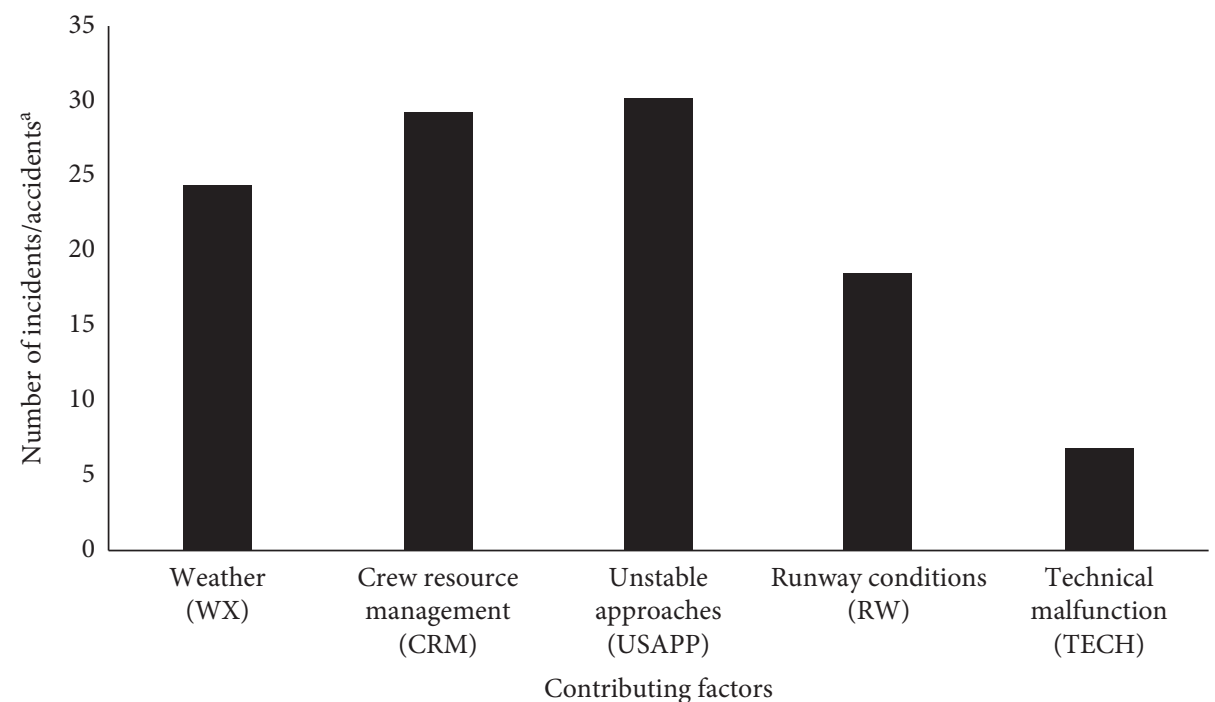

Figure 4: Distribution of contributing factors over the 44 Runway Excursion incidents/accidents. ${ }^{a}$ Note that more than one contributing factor was possible for each occurrence.

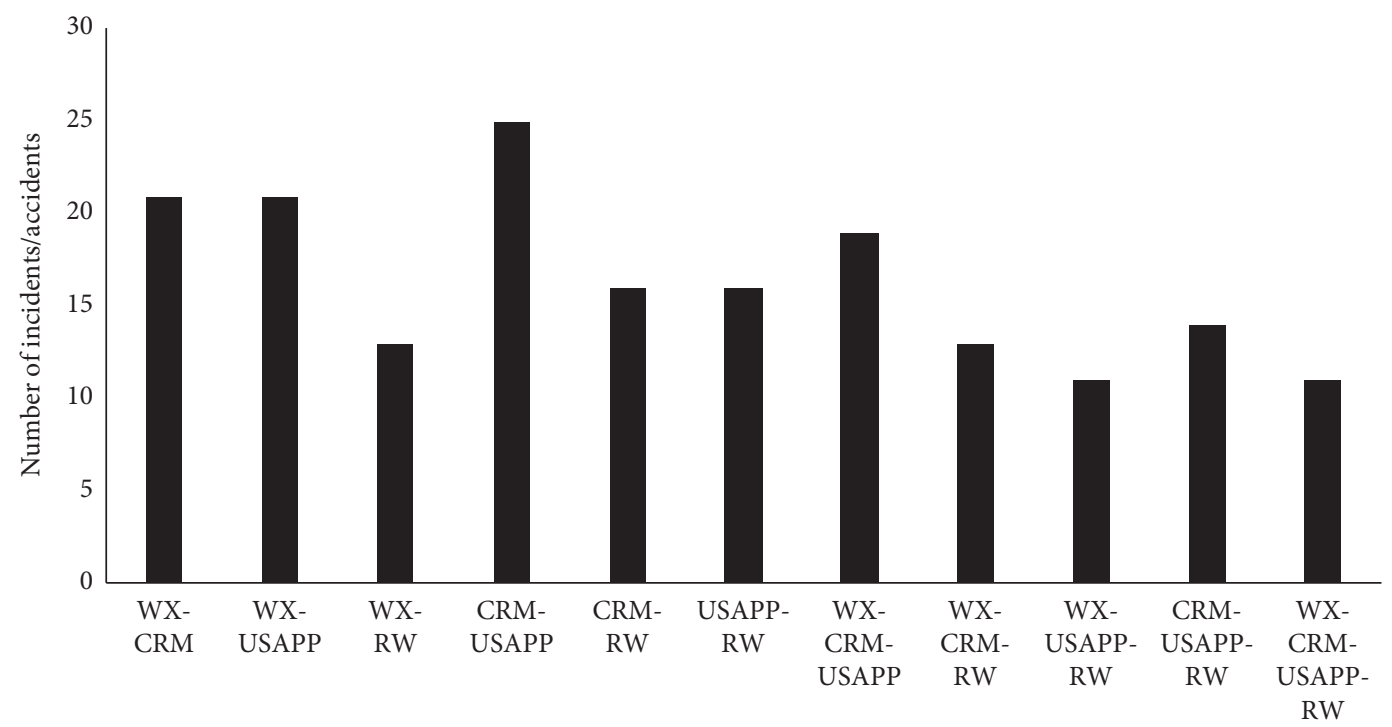

Multiple contributing factors

Figure 5: Distribution of multiple contributing factors over the 44 Runway Excursion incidents/accidents. Note. The following abbreviations are used: weather (WX); Crew Resource Management (CRM); Unstable Approaches (USAPP), and Runway Conditions (RW).

3.5. Incidents/Accidents in Mountainous Regions. Papua Island, which is characterised by mountainous regions, was significant as a location of 29 of 84 incidents/accidents and nine of 24-fatal accidents across Indonesia. By contrast, Java and Sumatera were the next highest as the location of 13 incidents/accidents each. Accordingly, factors contributing to the incidents in Papua were further examined.

Figure 6 shows that Papuan incidents/accidents involved a large number of Runway Excursions. These were usually nonfatal while CFIT events, which were less common, contributed with more fatalities. In addition, LOC-I, which occurred less often than the CFIT events, also contributed to fatal accidents. There were nine fatal incidents in Papua. This figure also shows that there was no incident involving wrong-runway landing in Papua island.

It is evident that technical malfunctions, while playing a role, are only mentioned in four incident/accident reports, while CRM issues were by far the most prevalent. Other factors of weather and Unstable Approaches were also significant. In terms of dual or multiple factors (Figure 7), the pair of WX-CRM played the largest role, followed by CRM-USAPP. The WX-CRM-USAPP combination played the largest triplet role, closely followed by the triplet of CRM-USAPP-RW.

For Runway Excursions, the triplet of WX-CRM-USAPP was the most common combined contributor. The 


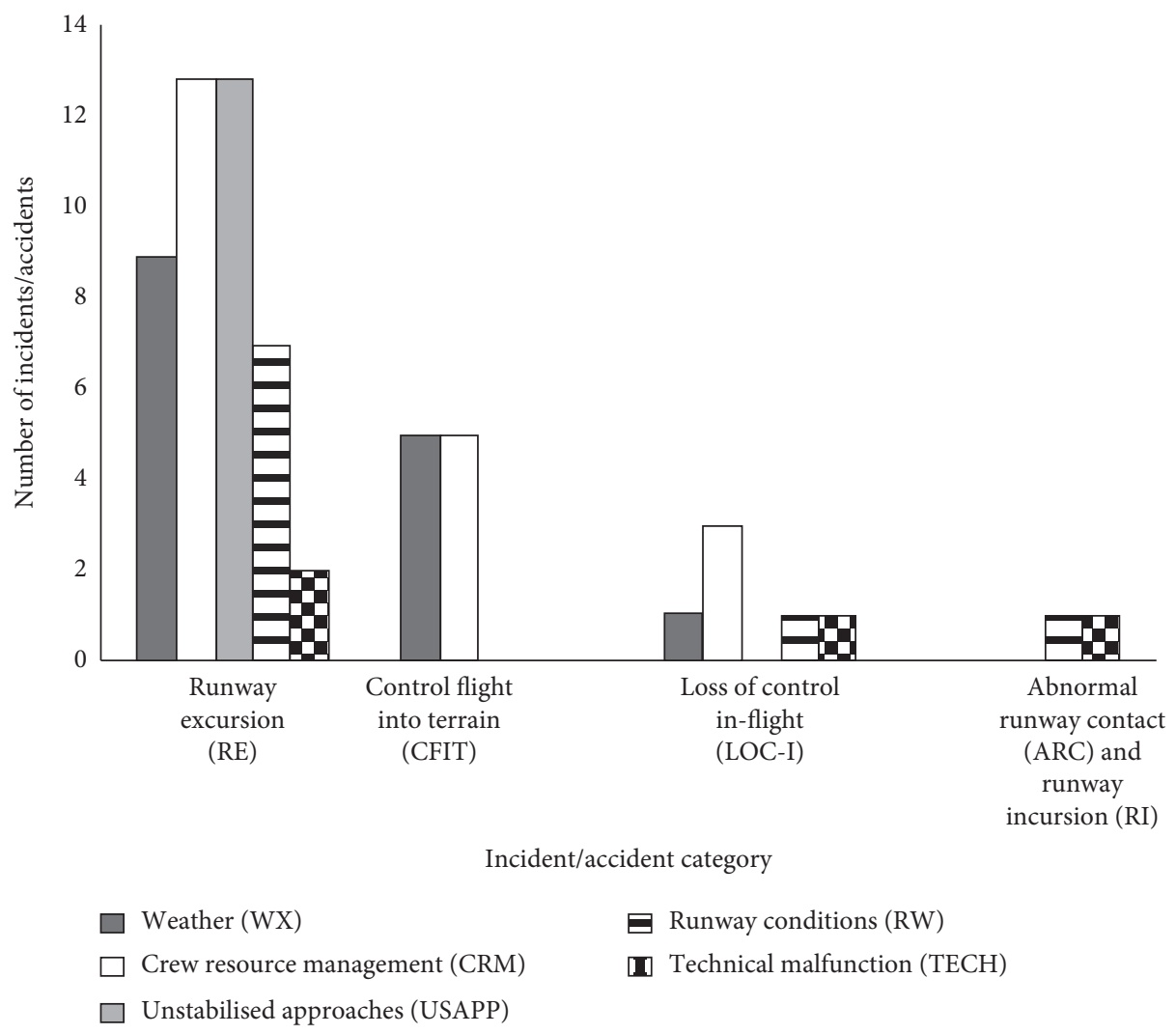

FIgURE 6: Distribution of contributing factors over the 29 incidents/accidents on Papua Island. Note. More than one contributing factor was possible for each occurrence.

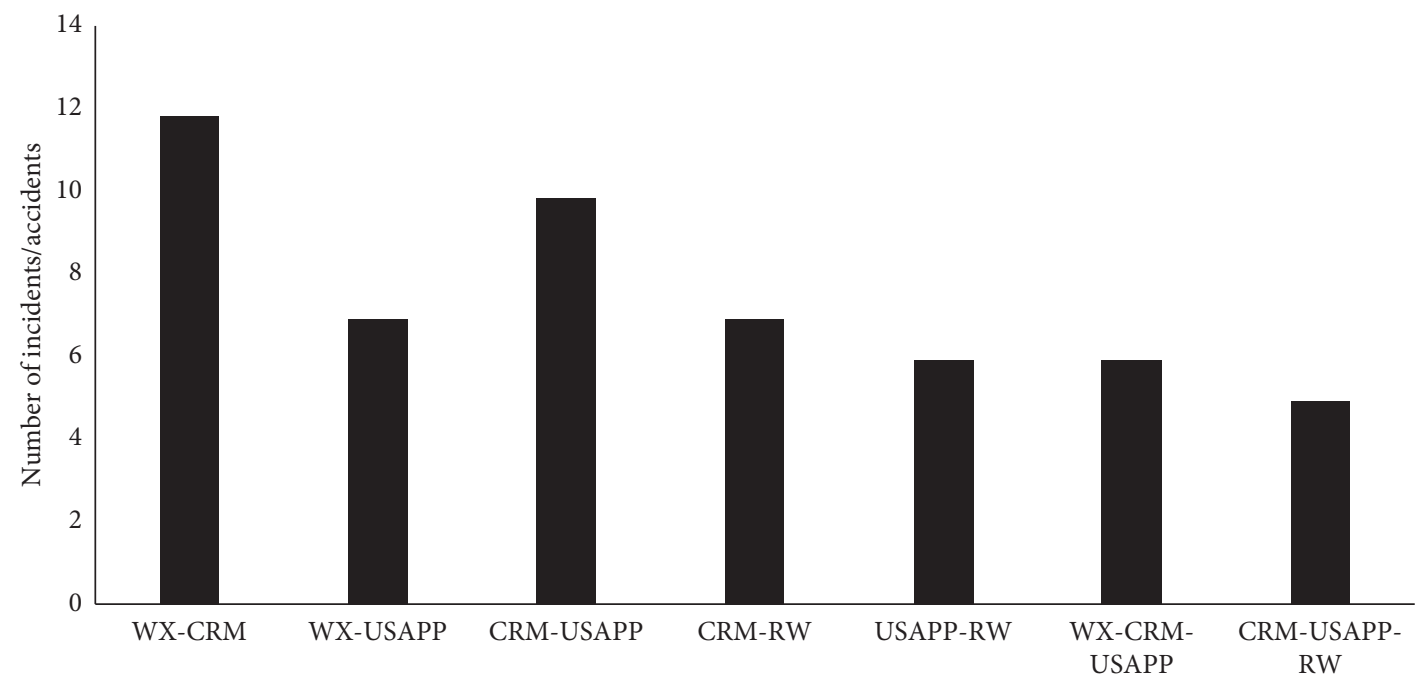

Multiple contributing factors

Figure 7: Distribution of multiple contributing factors over the 29 incidents/accidents on Papua Island. Note. The following abbreviations are used: weather (WX); Crew Resource Management (CRM); Unstable Approaches (USAPP), and Runway Conditions (RW).

occurrences in Papua, of the pair of WX and CRM, were more important, although the two combinations contributed equally at approximately $40 \%$. In Papua, weather was shown to be an important factor in fatal accidents.
All fatal CFIT accidents were weather-related, and the wreckages were often found at an elevation of at least 8,000 feet which imply that the aircraft were quite possibly in cloud among higher mountains and not visual. Although the final 
height of aircraft position was not clarified in one investigation report, the report indicated that flight crew experienced a Loss of Visual Reference when flying into cloud prior to the incident. Two investigation reports indicated that a deliberate flight deviation from the company's prescribed visual routes was a factor in the incident $[33,34]$. Anecdotally, deliberate flight deviations when flying VFR arise when pilots feel pressured to complete the flight, regardless of poor weather. These reports suggest that these actions were taken by pilots without sufficient prior assessment of the risk of colliding with terrain. For the LOC-I events the wreckage of aircraft was found near ridges of mountainous areas. In these occurrences the aircraft experienced a stall condition followed by improper corrective actions.

For nonfatal incidents, there were often other factors in play. These include the operator's safety management, meteorological facilities, and airstrip information [35]. In some cases it appears that management did not have routefamiliarisation programs for newly recruited pilots or failed to oversight the training or familiarisation programs, leading to an incident/accident $[34,36]$. Furthermore, putting crew in a pair for the first time as well as assigning crew who had not recently flown to airstrips that were considered as highrisk also contributed to incidents [37, 38]. In addition, having no access to meteorological information at some airstrips increases pilots' workload and leads to poor decisions when poor weather is encountered [39].

\section{Discussion}

In this study we have analysed the incident/accident investigation reports for aviation occurrences in Indonesia occurring between 2007 and 2015, providing for the firsttime detailed analyses of occurrence event types and of contributing factors. Multiple factors contributed to these occurrences, with Crew Resource Management, weather, and Unstable Approach being the most important of these, followed by Runway Conditions and technical malfunction. Runway excursions were the most prevalent type of incident during this period, followed by Loss of Control In-Flight, Controlled Flight into Terrain, and the remaining three categories, Abnormal Runway Contact, Runway Incursion, and wrong-runway landings. The following discusses the major factors contributing to the incidents in Indonesia, discusses how these compare internationally, and highlights potential ways forward in improving Indonesian Aviation safety practice.

\subsection{Crew Resource Management and Communication.} CRM was the most prevalent contributor to aviation occurrences in Indonesia during the period studied. Theory of the development and improvement of CRM suggests that in training and in practice, CRM should consider cultural preferences of individuals involved $[40,41]$. Consistent with such theory, a range of background issues may contribute to poor CRM in Indonesian aviation, including CRM training and issues of national and professional culture. There has been an increased focus recently on the training of pilots internationally, with multicrew training now compulsory for airline pilots in Australia and other countries including the USA and Canada [42-44]. This is also the case in Indonesia. However, poor communication between Indonesian crewmembers is evidenced by the large contribution of poor CRM to many nonfatal and fatal accidents [45]. (Fatal accident: accident where at least one passenger or crewmember is killed or later dies of their injuries, resulting from an operational accident. Events such as slips, trips and falls, food poisoning, or injuries resulting from turbulence or involving onboard equipment, which may involve fatalities, but where the aircraft sustains minor or no damage, are excluded.) The incident/accident investigation reports often recommended that crew training was insufficient in the area of CRM and that this needed to be addressed [46-49]. More recent studies of CRM indicated that this is an ongoing issue and even involves other crew outside the flight deck, such as cabin crew $[50,51]$, air traffic controllers (ATC) $[52,53]$, and flight dispatchers [54].

These factors are often exacerbated by hierarchical structures and poor communication among pilots. A number of the incident/accident investigation reports indicated that miscommunication between pilots and copilots was often a major cause [46, 47, 55, 56]. M. Mulder [57] defined power distance as the degree of inequality in power between a less powerful individual and a more powerful other, in the same social system. Some global fatal incidents around the world have been associated with power distance issues in the cockpit, for example, Asiana Airlines Flight 214 and KLM Flight 4805 [58, 59]. The accident investigation findings suggested the critical role of crew cultural factors as it could give an impact to pilot performance. The accident of KLM Flight 4805, also known as "Tenerife" showed the importance of the controller clearance for pilots on the deck, particularly in poor weather condition, and that the pilot flying must listen to crew comment. The role of broader cultural dimensions influencing communication and coordination on the flight deck has been confirmed by several researchers, including $[60,61]$. Similarly, some Indonesian incident/accident investigation reports have found that the first officers did not call out, cross-check, question, or challenge Captains in many of the critical situations leading up to an incident, particularly where a newly recruited pilot was involved $[46,47,55,56]$. The steep authority gradient was offered as an explanation by an investigator in an incident where the first officer, functioning as a pilot monitoring, did not take control of the aircraft when he deemed safety to have been compromised, but instead only offered verbal warnings [48]. In another incident, it was suggested that a Captain who failed to order a missed approach, or take over flying from the copilot, did so because of a heightened cockpit authority gradient due to the copilot being a Director General of Civil Aviation flight operations inspector [49].

Indonesians have been identified as having a relatively higher power distance index culturally, compared to those from other Asian countries and Australians [62, 63]. Indonesian culture, which is highly patriarchal and hierarchical, is an important factor to consider when considering 
the role CRM plays in incidents [64]. In the IATA safety report of 2015 [11], the Chairman of the Accident Classification Task Force questioned whether it is individual frontline actions or the attitude within the Indonesian culture that stretches far beyond the individual that contributes to the higher national accident rates. Alam [65] suggested that such a culture would require more vigorous intervention for successful cockpit learning than other low power distance cultures. The extent to which this type of behaviour impacts CRM in Indonesia and how to shape plans for improvement in this area warrants further investigation.

In addition to power distance, previous studies have suggested that the failure of CRM might be attributable to the cultural factors of the flight crew $[40,58,66]$. Research has been conducted to look at the impact of different cultures, namely, Eastern and Western cultures, on the performance of pilots in the cockpit $[65,67]$. However, within the Indonesian archipelagic territory, there are over 1,300 tribes that are scattered amongst 17,508 islands, with the Javanese ethnic group being identified as a dominant amongst other groups [68]. Ananta and Arifin [69] noted that Javanese made up slightly over 40 per cent of Indonesians. As a consequence of the dominance of the Javanese, Irawanto and Ramsey [70] claimed that social structural societies include Indonesian public sector institutions run in "Javanese style." Javanese style, which is strongly characterised by social qualities, including "tepa selira" (known as a mutual respect), is a factor to the high Indonesian power distance score and consequently, it may impact the way Indonesians communicate with others. Being less assertive and less direct in communication are behaviours that characterise typical "Javanese style." This could become an important concern in relation to multicrew communication in the cockpit. It is possible that cultural issues such as power distance may interact with cultural differences based on more local, or subcultural factors, given the particular cultural diversity present in Indonesia.

4.2. Terrain and Weather. Along with issues around CRM and training, the uniqueness of Indonesia's terrain and weather also played a critical role in aviation incidents, with $58 \%$ of the incidents that we examined including the contributing factor of weather such as rain or wind. This may account for some of the variation when comparing the Indonesian data to global incident rates. R.K. Jenamani and A. Kumar [19] noted that weather only contributed to $8 \%$ of commercial incidents in the US. The ASC [71] found that this figure was $16.3 \%$ in Taiwan, while [72] noted a global average of between 21 and $26 \%$. This variation in rate is even more pronounced when one considers that the lower contribution of weather in other locations occurs despite the fact that they include consideration of wider weather conditions in these figures, such as snow and ice.

There are a variety of reasons why weather plays a larger role in Indonesian aviation incidents. In scenarios where poor weather was encountered, visibility was often a determining factor for the severity of the incident; that is, the presence of clouds was identified as a major factor for fatal accidents in Papua, while for nonfatal incidents, rain and wind were more critical. At times pilots were flying off-track to avoid cloud and then entering cloud either inadvertently or deliberately [33,34, 46, 73-75]. These events involved more aircraft flown under Visual Flight Rules (VFR) and fewer flights under Instrument Flight Rules (IFR). For the incidents involving VFR flights, investigation reports indicated that there were events where pilots may have experienced spatial disorientation because of lack of visual reference, leading to Controlled Flight into Terrain $[33,46,75,76]$. Further, in IFR occurrences, the incident/ accident investigation reports suggested that spatial disorientation due to pilots being unfamiliar with an airport environment was a contributing factor, despite onboard navigational instruments. It was suggested that this was due to both an absence of on-ground navigational support and a lack of a published instrument approach and landing procedure $[77,78]$. However, even when both of these were available, incidents were still occurring due to a loss of situational awareness by the pilots when entering a rain cloud during the final approach below Minimum Descend Altitude (MDA) [79]. Therefore, having a shared team performance among multiple crew in the cockpit is critical, particularly during approach and landing where pilots decision has to be made upon crew's mutual situational awareness [66, 80]. The unserviceability of airports/airstrips and/or a lack of meteorological information may have contributed to incidents, particularly in Papua $[33,46,75,76]$ as well.

4.3. Major Airport Runway Excursions. A combination of both CRM issues and adverse weather conditions, as well as other factors such as technical failure, may be the reasons for the increased presence of unstable approach-related Runway Excursions in Indonesia. Most of the investigation reports examined aircraft Cockpit Voice Recorder (CVR) to analyse pilot's performance; however in some cases the CVR were unserviceable or overwritten. Some reports identified that prior to incidents/accidents a crew briefing was not performed in the cockpit, leading to the miscoordination of pilots that resulted in an undesired aircraft state, including an unstable approach. In addition, company pressures to land immediately after an unstable approach can often lead to Captains ignoring CRM philosophies and procedures by overriding or ignoring first officer comment or advice. There are many other ways in which it might, and since poor CRM is such a broad risk factor, we have discussed this only generally here. During the period studied, there were 97 commercial flight incidents, and 45\% involved Runway Excursions, most of these being in Java. This is a much higher rate of Runway Excursion compared to other parts of the world where, on average, Unstable Approaches are a less important contributing factor for commercial operations than we have observed for Indonesia. For example, in Taiwan between 2007 and 2016, only 28\% of incidents involve Runway Excursions, while internationally between 2008 and 2016 the figure is $34 \%$ [71, 81]. 
When there are issues with CRM, weather can become a significant factor in the occurrences involving an unstable approach in a jet aircraft in Indonesia. Degraded visibility as a resulted of winds, heavy rain, and cloudy conditions can create circumstances leading to an Unstable Approach. Unstable Approaches occur due to excessive speed, glide slope deviations, and localizer azimuth deviations of the runway and can result in floating landings with a touchdown beyond the normal touchdown zone. Flying Unstable Approaches, while not always lead to an excursion, are recognised as a significant risk factor for excursions. Based on the Flight Safety Foundation findings of 2006, Moriarty and Jarvis [82] suggested that landing in a stable approach is 60 times safer than that in unstable one. Therefore, discontinuing or performing a missed approach when an unstable approach occurs is essential, as recognised by company SOPs.

Runway surface conditions were identified as a factor common to the Indonesian Runway Excursion incidents. Landing on a wet runway is between 8 and 13 times riskier than landing on a dry runway [83]. Wet and contaminated runway surfaces might be a result of inadequate maintenance, standing water, or rubber deposits on the runway as well as the lack of runway friction information. Braking information provided in the Aircraft Flight Manual is dependent on Runway Conditions [84]. These wet and contaminated surfaces of runway decrease aircraft deceleration and reduced runway friction will extend runway landing distance. Information relating to the current Runway Conditions is essential, so that incoming and outgoing flights can understand the condition of the runway in use. Also, airport operators have a responsibility to conduct runway surface checks periodically as well as informing air operators of the relevant friction performance. Some incident/accident investigation reports indicate that this may not be happening in Indonesia at least some of the time $[47,85,86]$.

Information on braking action across Indonesian airports is not provided by airport authorities [87]. Indonesia currently has 299 airports across its territory [88], 76 of which are classified as "major airports" where the runway dimensions exceed 1,800 $\mathrm{m}$ in length, and large jet aircraft (such as B 747/ $\mathrm{B}, 777 / \mathrm{B}, 737$, or $\mathrm{A} 320$ ) are able to operate. Of the remaining 223 airports, 102 have runway dimensions less than 800 meters [89]. These 102 airports are mostly less developed, particularly those located in remote areas such as Papua. Airstrips are more numerous than airports in these locations, and these airstrips tend to be operated with limited resources in terms of meteorological, navigational, or radio communication aids. A number of airstrips in Papua are considered to be poorly developed and most of them only serve visual flights because of a lack of suitable navigation aids [90]. In addition, only four Papuan airports have a Terminal Controlled Area (TMA), which provides air traffic control support within a limited local radius for flights. Radar is also rare so that flights must be performed visually [90], or by reference to air navigation aids which are also rare.

4.4. Incidents/Accidents in Papua. The result of a combination of CRM, training, and weather is highlighted in the increased rate of fatal incidents in Papua, where steep topography, unpredictable weather, and short narrow landing fields create the most difficult flying conditions in Indonesia. Papua accounted for $35 \%$ of the 84 commercial occurrences from 2007 to 2015 which have been considered here, with a higher rate of fatal incidents when compared to the other islands. All of these fatal accidents occurred when the aircraft were performing visual flights and most of them were turboprop aeroplanes. In many cases, there was no Flight Data Recorder or Cockpit Voice Recorder fitted to the smaller aircraft. The incident/accident investigation reports suggested that the fatal flights involved a "VFR into IMC" situation and these were also associated with a breakdown of CRM, which is magnified in these conditions. The investigation reports also indicated that the decisions to fly into IMC coupled with inadequate implementation of CRM were a consequence of inadequate training and the unfamiliarity of mountainous weather and geographical terrain. LOC-I and CFIT occurrences were not necessarily associated with monsoon weather, but probably to weather patterns unique to mountainous areas, where atmospheric processes promote the establishment of cloud and rainfall in Papua.

While operating the aircraft according to company procedures and the aircraft's flight manual is exceedingly important, the investigators suggested that most accidents occurred due to poor judgment in adverse weather circumstances and deviation from the SOPs issued by the operators. They also suggested that safety related issues of mountain flying require practical experience obtained under the guidance of a pilot who has flown specific routes many times before and can make sensible judgments about the likelihood of a successful visual approach.

Anecdotally, inadequate training and a lack of standardised captaincy qualifications have been identified as factors which contribute to the occurrences. Flying in mountainous areas and in uncontrolled airspace such as in Papua involves dealing with weather factors such as orographic cloud, rainfall, frequent changes in wind direction, and turbulence. These conditions require considerable judgment skills for pilots that can only be obtained with experience. Many of the incident/accident investigation reports indicate lack of flying experience, including a lack of familiarisation with air route or airport location, as contributing factors [34, 36, 77]. Mountain flying is a specific skill for pilots, but training in mountain flying is not taught in any depth at Indonesian flying schools. Pilots only develop these skills while working for airlines operating in the mountainous areas. Consequently, the development of mountain flying skills differs from one airline to another, and we could not locate any standardised syllabus issued by the Indonesian DGCA. In addition, captaincy qualification for mountain flying is varied among operators. In some incidents it was noted that some pilots had minimum flight hours on type $[91,92]$. This might be an indication that there is no standard DGCA regulation for captaincy qualification, particularly in Papua. Based on incident/accident investigation report safety recommendations, one major airline flying in Papua has increased the minimum required flying hours from 1,000 to 1,500 hours for first-officer pilots to 
become Pilot In Command [77, 93]. It will be interesting to review whether this change in standards leads to a decreased rate of incidents in this area.

4.5. Strengths and Limitations. One of the strengths of the study is the requirement under national law that all aviation accidents and serious incidents are reported to the NTSC. Therefore, we can be confident that our study has covered all the occurrences of this nature in the time period in question. Furthermore, the incident/accident investigation reports (particularly the recommendation sections) have been discussed by all parties involved, including the regulatory body, airport authority, air navigation Indonesia, air operator, aircraft manufacturer, and designer, and, in some cases, experts from foreign safety boards and academics.

The study has a number of limitations. Not all incidents have been thoroughly investigated, as at the time of analysis, 18 were still listed as having a "preliminary status." This could be due to a variety of reasons, including a lack of reliable or available sources, such as the shortage of investigators. The current politics and prevailing regulation, based on budget allocation, regulate that the number of air investigators should not exceed 10 persons [94]. This is arguably insufficient to cover a whole Indonesian territory and a wide range of contributing factors. Secondly, not all incidents have been investigated by NTSC. Those not considered an accident nor a serious incident may be investigated internally by the air operator. During the period of incidents studied, there were a further 202 incidents that were internally investigated by the operators [95]. If these were able to be analysed, by being collated into a central database, they may shed further light on the factors discussed in this paper, as well as other potential contributing factors $[23,96]$. The nature of the investigation reports themselves can represent limitations for any study of factors contributing to incidents as the reports considered human, technical, and environmental factors and fail to delve more deeply into the possible influence of societal or cultural factors [18]. Studies based on incident reports are limited by the nature of the information available, including structures and the methodologies used to construct patterns and variations in investigation and reporting procedures in different jurisdictions [96]. Nonetheless, the incident/accident investigation reports as used in this study constitute the best available data from which to derive patterns and trends in Indonesian aviation incidents. All in all, although learning from postincident reports is important for the quality of reports is varied from one to other States.

\section{Conclusions}

The methodology used here is basic, yet effective, and has identified for the first time that the types of accidents comprise mainly Runway Excursions by jet transport aircraft at major airports in flatland regions, and fatal accidents which occur in highland areas due to Controlled Flight into Terrain. The study is primarily data-driven, yet the reports show clear evidence that weather and poor crew communication provide uniquely difficult circumstances in terms of civil aviation safety. Further the results presented here will provide the basis for studies involving greater depths of analyses.

In terms of Runway Excursions there is some evidence that organisational influences play a role in that safety related cultures appear to be less well developed at management level. Lack of adherence to standard operating procedures (SOPs) and poor Crew Resource Management (CRM) is common and contributes to the continuation of instrument approaches which ideally should have been discontinued through being unstable. Unstable Approaches seem to be often occurring in poor weather, and their continuation results in the aircraft being too high, too fast, or nonaligned when visually over the runway threshold, and steering and braking on touchdown can be affected by poor runway condition. Fortunately, the high rainfall occurring on and around major coastal airports ensures that surrounding grounds are very wet and soft, and Runway Excursions are most often nonfatal.

In the highlands, mainly Papua, most flying is visual, and there are pressures to operate during the early part of the day when the weather is usually better. In addition, many highland communities have no road transport so there is pressure on organisations and pilots to satisfy the high demand for air services. Mountain flying requires pilots to be experienced in understanding the weather influences and topography of specific airports and approaches and most flying is visual. Yet there appears to be no specific mountain flying syllabus or guide available in basic training and pilots are taught mountain flying "on the job." In mountain regions, decisions to continue visual flight into cloud or rain, or to deviate from standard routes, often lead to Controlled Flight into Terrain, or loss of control.

In summary, this paper describes analyses of civil aviation safety occurrences in Indonesia, which have been officially investigated, and highlights significant safety related issues which are quite different from those which occur in other ICAO states. References $[45,97]$ identified that insufficient regulatory oversight and Safety Management System were factors that contributed the most to the global incidents/accidents during 2010-2018. Worldwide, poor visibility and terrain/obstacles contributed less to the Runway Excursion events, yet they are a major factor in Controlled Flight into Terrain incidents [97, 98]. However, in Indonesia the unique combination of high rainfall and mountainous terrain, along with Crew Resource Management, training and hierarchical issues, provide significant risks leading to higher incident rates compared to many other parts of the world. While weather cannot be changed, better CRM and better training can mitigate the risk posed to the aviation industry. To effect this change, a better understanding of cultural and hierarchical factors is required, to enable more vigorous intervention for successful cockpit learning and enhance training for some aspects of flight. 


\section{Data Availability}

The incident/accident report data used to support the findings of this study are publicly available, at the online locations specified in the paper.

\section{Conflicts of Interest}

The authors declare that they have no conflicts of interest.

\section{Acknowledgments}

The authors wish to thank the Indonesia Endowment Fund for Education (Lembaga Pengelola Dana Pendidikan), the Indonesian Ministry of Finance, the Republic Indonesia for its Presidential scholarship and funding support for this research; and the Indonesian Ministry of Transportation; the Indonesian National Transportation Safety Committee; and Air Navigation Indonesia and Captain Rama Noya, acting as the President of Indonesian Pilot Association as well as the authors' colleagues: Colonel Aviator Supriabu, Major Aviator Brahmana, Captain Teddy, Captain Fajar, Captain Joppy, Mr. David, and Mr. Sayuta for their generous support.

\section{References}

[1] P. Niewiadomski, "Global production networks in the passenger aviation industry," Geoforum, vol. 87, pp. 1-14, 2017.

[2] N. Maille, "Modeling airline crew activity to improve flight safety analysis," in Proceedings of the IEEE Aerospace Conference, Big Sky, MT, USA, March 2017.

[3] ICAO, "Air navigation report," Capacity \& Efficiency, ICAO, Montreal, Canada, 2016, https://www.icao.int/airnavigation/ Documents/ICAO_AN\%202016_final_19July.pdf.

[4] C. V. Oster, J. S Strong, and C. K. Zorn, "Analyzing aviation safety: problems, challenges, opportunities," Research in Transportation Economics, vol. 43, no. 1, pp. 148-164, 2013.

[5] ICAO, 2012 Safety Report, ICAO, Montreal, Canada, 2012, https://www.icao.int/safety/Documents/ICAO_SGAS_2012_ final.pdf.

[6] ICAO, Safety Report 2017, ICAO, Montreal, Canada, 2017, https://www.icao.int/safety/Documents/ICAO_SR_2017_ 18072017.pdf.

[7] BPS, Statistical Yearbook of Indonesia 2010, Badan Pusat Statistik, Jakarta, Indonesia, 2010, http://istmat.info/files/ uploads/47405/statistical_yearbook_of_indonesia_2010.pdf.

[8] BPS, Statistical Yearbook of Indonesia 2018, Badan Pusat Statistik, Jakarta, Indonesia, 2018, http://istmat.info/files/ uploads/60411/statistical_yearbook_of_indonesia_2018.pdf.

[9] ICAO, Accident Statistics, ICAO, Montreal, Canada, 2019, https://www.icao.int/safety/iStars/Pages/Accident-Statistics. aspx.

[10] M. E. Lestiani, G. Yudoko, H. Yassierli, and H. Purboyo, "Developing a conceptual model of organizational safety risk: case studies of aircraft maintenance organizations in Indonesia," Transportation Research Procedia, vol. 25, pp. 136-148, 2017.

[11] IATA, IATA Safety Report 2015, IATA, Montreal, Canada, 2016, https://skybrary.aero/bookshelf/books/3408.pdf.

[12] IATA, Safety Report 2017, https://aviation-safety.net/ airlinesafety/industry/reports/IATA-safety-report-2017.pdf,
IATA, Montreal, Canada, 2018, https://aviation-safety.net/ airlinesafety/industry/reports/IATA-safety-report-2017.pdf.

[13] S. Hradecky, Incident: Lion B738 at Pontianak on Feb 16th 2019, Overran Runway on Landing, http://avherald.com/h? article $=4 \mathrm{c} 447454,2020$.

[14] KNKT, Aircraft Accident Investigation Report-Final Report No KNKT.18.10.35.04; PT. Lion Mentari Airlines Boeing 737-8 (MAX); PK-LQP Tanjung Karawang, West Java Republic of Indonesia-29 October 2018, National Transportation Safety Committee, Jakarta, Indonesia, 2018, http://knkt.dephub.go. id/knkt/ntsc_aviation/aaic.htm.

[15] A. Barnett, "Cross-national differences in aviation safety records," Transportation Science, vol. 44, no. 3, pp. 322-332, 2010.

[16] L. Carnis and E. Yuliawati, "Nusantara: between sky and earth could the PPP be the solution for Indonesian airport infrastructures?" Case Studies on Transport Policy, vol. 1, no. 1-2, pp. 18-26, 2013.

[17] R. A. Nugraha, "Improving aviation safety in Indonesia: how many more accidents?" Hasanuddin Law Review, vol. 2, no. 3 , pp. 328-348, 2016.

[18] G. B. Pratama, A. Widyanti, and I. Z. Sutalaksana, "Incorporating Hofstede'National culture in human factor Analysis and classification system (HFACS): cases of Indonesian aviation safety," in Proceeding of the MATEC Web of Conferences, EDP Sciences, Singapore, February 2018.

[19] R. K. Jenamani and A. Kumar, "Bad weather and aircraft accidents-global vis-à-vis Indian scenario," Current Science, vol. 104, no. 3, pp. 316-325, 2013.

[20] R. Mo, "Mid-mountain clouds at whistler during the vancouver 2010 winter olympics and paralympics," Pure and Apllied Geophysics, vol. 171, no. 1-2, pp. 157-183, 2014.

[21] D. R. Hunter, M. Martinussen, M. Wiggins, and D. O'Hare, "Situational and personal characteristics associated with adverse weather encounters by pilots," Accident Analysis \& Prevention, vol. 43, no. 1, pp. 176-186, 2011.

[22] R. I. C. Bartch, Aviation Law in Australia, Thomson Reuters, Sydney, Australia, 4th edition, 2013.

[23] M. T. Baysari, C. Caponecchia, A. S. McIntosh, and J. R. Wilson, "Classification of errors contributing to rail incidents and accidents: a comparison of two human error identification techniques," Safety Science, vol. 47, no. 7, pp. 948-957, 2009.

[24] G. S. Braut and O. Nja, "Learning from accidents (incidents)— theoretical perspectives on investigation reports as educational tools," in Reliability, risk and safety theory and applications: proceedings of the European Safety and Reliability Conference, ESREL 2009, CRC Press, Prague, Czech Republic, pp. 43-50, March 2009.

[25] BPS, Statistical Yearbook of Indonesia 2015, Statistik Indonesia, 2015, http://istmat.info/files/uploads/47409/statistical_ yearbook_of_indonesia_2015.pdf.

[26] J. Hays, "Weather and climate in Indonesia," 2015, http:// factsanddetails.com/indonesia/Nature_Science_Animals/sub 6_8a/entry-4079.html.

[27] KNKT, Data Investigasi Kecelakaan Penerbangan Tahun 2010-2016, Media Release National Transportation Safety Committee, Jakarta, Indonesia, 2016, http://knkt.dephub.go. id/knkt/ntsc_home/Media_Release/Media\%20Release\%20K NKT\%202016/Media\%20Release\%202016\%20-\%20IK\%20P enerbangan\%2020161130.pdf.

[28] ICAO, Aviation Occurrence Categories", ICAO Commercial Aviation Safety Team, Montreal, Canada, 2011, https://www. icao.int/APAC/Meetings/2012_APRAST/OccurrenceCategory Definitions.pdf. 
[29] IATA, Safety Report 2016, IATA, Montreal, Canada, 2017, http://www.iata.org/docx/IATA-Safety-Report-2016-2.pdf, 53rd edition.

[30] ICAO, "Annex 13 to the convention on international civil aviation-aircraft accident and incident investigation," EMSA Eropa, Montreal, Canada, 2016, https:/www.emsa.europa.eu/ retro/Docs/marine_casualties/annex_13.pdf.

[31] KNKT, Major Accident Investigation Guidelines 2017, KNKT, Jakarta, Indonesia, 2017, http://knkt.dephub.go.id/knkt/ntsc_ aviation/Investigator\%20Area/1\%20Peraturan\%20dan\%20re frensi\%20terkait\%20Investigasi\%20Kecelakaan/2\%20Aturan \%20Internal\%20KNKT/KNKT\%20Major\%20Accident\%20In vestigation $\% 20$ Guidelines\%202nd\%20Edition.pdf.

[32] R. Hidayat, "Modulation of Indonesian rainfall variability by the madden-julian oscillation," Procedia Environmental Sciences, vol. 33, pp. 167-177, 2016.

[33] KNKT, Aircraft Accident Investigation Report-Final Report No.KNKT.15.10.21.04-DHC-6 Twin Otter; PK-BRM; District of Luwu, South Sulawesi-2 October 2015, NTSC Reports, Jakarta, Indonesia, 2016, http://knkt.dephub.go.id/knkt/ntsc_ aviation/aaic.htm.

[34] KNKT, Aircraft Accident Investigation Report-Final Report No.KNKT.09.04.13.04 Pilatus Porter PC-6 PK-LTJ Mt. Gergaji, Papua 17 April 2009, NTSC Reports, Jakarta, Indonesia, 2009, http://knkt.dephub.go.id/knkt/ntsc_aviation/aaic.htm.

[35] IPI, Pemerintah Upayakan Peningkatan safety di Papua, Info Penerbangan, 2016, https://www.infopenerbangan.com/ pemerintah-upayakan-peningkatan-safety-di-papua/.

[36] KNKT, Aircraft Accident Investigation Report-Final Report No.KNKT.15.08.16.04-PAC-750XL; PK-KIG; Ninia Airstrip, Yakuhimo, Papua-12 August 2015, NTSC Reports, Jakarta, Indonesia, 2016, http://knkt.dephub.go.id/knkt/ntsc_ aviation/aaic.htm.

[37] KNKT, Aircraft Serious Incident Investigation Report-Final Report No.KNKT.13.02.03.04-DHC 6-300; PK-YRF; Apalapsili Aerodrome, Papua-5 February 2013, NTSC Reports, Jakarta, Indonesia, 2014, http://knkt.dephub.go.id/knkt/ntsc_ aviation/aaic.htm.

[38] KNKT, Aircraft Accident Investigation Report-Final Report No.KNKT.09.06.12.04; Dornier 328-100; PK-TXN; Tanah Merah Airport, Boven Digoel, Papua-14 June 2009, NTSC Reports, Jakarta, Indonesia, 2012, http://knkt.dephub.go.id/ knkt/ntsc_aviation/aaic.htm.

[39] IPI, Minute of Meeting (MoM) Forum Diskusi Mengenai AFIS di Remote Area, http://ipi.or.id/minutes-of-meeting-momforum-diskusi-mengenai-afis-di-remote-area/, 2017.

[40] R. L. Helmreich and A. C. Merritt, Culture at Work in Aviation and Medicine: National, Organizational and Professional Influences, Routledge, 2017.

[41] A. Merritt, "Culture in the cockpit," Journal of Cross-Cultural Psychology, vol. 31, no. 3, pp. 283-301, 2000.

[42] Transport Canada, Crew Resource Management, https://www. tc.gc.ca/media/documents/ca-opssvs/AC_700_042.pdf, 2019.

[43] CASA, "Integration of human factors (HF) into safety management systems (SMS)," 2009, https://www.casa.gov.au/ file/105171/download?token=klZ.

[44] FAA, Crew Resource Management Training (AC No: 120-51E, 2004.

[45] IATA, Safety Report 2018, IATA, Montreal, Canada, https:// libraryonline.erau.edu/online-full-text/iata-safety-reports/IATASafety-Report-2018.pdf, 2019.

[46] KNKT, Aircraft Accident Investigation Report-Final Report No.KNKT.11.09.20.04-Casa 212-200; PK-TLF; Leuser Mountain National Park; North Sumatera-29 September
2011, NTFS Reports, Jakarta, Indonesia, 2013, http://knkt. dephub.go.id/knkt/ntsc_aviation/aaic.htm.

[47] KNKT, Aircraft Serious Incident Investigation Report-Final Report No.KNKT.15.11.26.04-Boeing 737-900ER; PK-LBO; Adisutjipto International Airport Yogyakarta-6 November 2015, NTFS Reports, Jakarta, Indonesia, 2016, http://knkt. dephub.go.id/knkt/ntsc_aviation/aaic.htm.

[48] KNKT, Aircraft Accident Investigation Report-Final Report No.KNKT/07.06/07.02.35.—Boeing 737-497 PK-GZC Adi Sucipto Airport, Yogyakarta Indonesia 7 March 2007, NTFS Report, Jakarta, Indonesia, 2007, http://knkt.dephub.go.id/ knkt/ntsc_aviation/aaic.htm.

[49] KNKT, Aircraft Serious Incident Investigation Report-Final Report No.KNKT.08.04.09.04. Boeing 737-300; PK-CJC; Depati Amir Airport, Pangkal Pinang-18 April 2008, NTFS Reports, Jakarta, Indonesia, 2010, http://knkt.dephub.go.id/ knkt/ntsc_aviation/aaic.htm.

[50] R. D. Chute and E. L. Weiner, "Cockpit-cabin communication: I. A tale of two cultures," The International Journal of Aviation Psychology, vol. 5, no. 3, pp. 257-276, 1995.

[51] C. K. Kolander, "Flight and cabin crew teamwork: improving safety in aviation," in Crew Resource Management B, G. Kanki, J. Anca, and T. R. Chidester, Eds., pp. 407-420, Academic Press, U.K.; U.S, 2019.

[52] B. R. C. Molesworth and D. Estival, "Miscommunication in general aviation: the influence of external factors on communication errors," Safety Science, vol. 73, pp. 73-79, 2015.

[53] Q. Wu, B. R. C. Molesworth, and D. Estival, "An investigation into the factors that affect miscommunication between pilots and air traffic controllers in commercial aviation," The International Journal of Aerospace Psychology, vol. 29, no. 1-2, pp. 53-63, 2019.

[54] B. J. Hayward, A. R. Lowe, and M. J. W. Thomas, "The migration of crew resource management training," in Crew Resource Management, B. G. Kanki, J. Anca, and T. R. Chidester, Eds., pp. 421-447, Academic Press, Cambridge, MA, USA, 2019.

[55] KNKT, Aircraft Serious Incident Investigation Report-Final Report No.KNKT.15.02.04.04-ATR 72-600; PK-GAG; Lombok International Airport-03 February 2015, NTFS Reports, Jakarta, Indonesia, 2016, http://knkt.dephub.go.id/knkt/ntsc_ aviation/aaic.htm.

[56] KNKT, Aircraft Accident Investigation Report-Final Report No. KNKT.11.05.10.04-Xi'An Aircraft Industry MA60; PKMZK; Utarom Airport, Kaimana-Papua Barat-07 May 2011, KNKT, Jakarta, Indonesia, 2012, http://knkt.dephub.go. id/knkt/ntsc_aviation/aaic.htm.

[57] M. Mulder, The Daily Power Game. Leiden, the Netherlands: Mar-Tinus Nijhoff, Social Sciences Division, Oxford, UK, 1977.

[58] S. Chow, S. Yortsos, and N. Meshkati, "Asiana Airlines Flight 214," Aviation Psychology and Applied Human Factors, vol. 4, no. 2, 2014.

[59] R. V. Cowlagi and J. H. Saleh, "Coordinability and consistency in accident causation and prevention: formal system theoretic concepts for safety in multilevel systems," Risk Analysis, vol. 33, no. 3, pp. 420-433, 2013.

[60] N. Bienefeld and G. Grote, "Silence that may kill," Aviation Psychology and Applied Human Factors, vol. 2, no. 1, 2012.

[61] S. Zhu and W. Ma, "Culture's influence on cockpit communication," in Proceedings of the International Conference on Management, Computer and Education Informatization, Atlantis Press, Shenyang, China, September 2015. 
[62] A. A. Pekerti and S. Sendjaya, "Exploring servant leadership across cultures: comparative study in Australia and Indonesia," The International Journal of Human Resource Management, vol. 21, no. 5, pp. 754-780, 2010.

[63] D. W. Irawanto, "An analysis of national culture and leadership practices in Indonesia," Journal of Diversity Management (JDM), vol. 4, no. 2, pp. 41-48, 2009.

[64] O. Pruetipibultham, "Developing human resource development interventions to aid expatriates' cultural adaptation: insights to the Javanese culture," Human Resource Development International, vol. 15, no. 1, pp. 109-117, 2012.

[65] M. A. Alam, "Cockpit learning in power distant cockpits: the interaction effect of pilot's interdependence and inclination to teamwork in airline industry," Journal of Air Transport Management, vol. 42, pp. 192-202, 2015.

[66] D. Harris and W. C. Li, "Cultural determinants of error on the flight deck," The Handbook of Human-Machine Interaction: A Human-Centred Design Approach, pp. 399-416, Ashgate Publishing, Farnham, UK, 2011.

[67] M.-Y. Liao, "Safety Culture in commercial aviation: differences in perspective between Chinese and Western pilots," Safety Science, vol. 79, pp. 193-205, 2015.

[68] K. Mangkusubroto, Systems Science for Complex Policy Making: A Study of Indonesia, vol. 3, Springer, Berlin, Germany, 2016.

[69] A. Ananta and E. N. Arifin, Demography of Indonesia's Ethnicity, Institute of Southeast Asian Studies, Singapore, 2015.

[70] D. W. Irawanto, P. L. Ramsey, and D. C. Tweed, Exploring Paternalistic Leadership and its Application to the Indonesian Context, 2012.

[71] ASC, Taiwan Aviation Occurrence Statistics 2007 to 2016, Aviation Safety Council, Taipei, Taiwan, 2017, https://www. asc.gov.tw/upload/statistics_files/Taiwan\%20Aviation\%20Oc currence\%20Statistics\%202007-2016.pdf.

[72] L. Spirkovska and S. K. Lodha, "AWE: aviation weather data visualization environment," Computers \& Graphics, vol. 26, no. 1, pp. 169-191, 2002.

[73] KNKT, Aircraft Accident Investigation Report-Final Report No. KNKT.12.08.16.04-PA-31-350; PK-IWH; Mayang Hill, Bontang, East Kalimantan-24 August 2012, National Transportation Safety Committee, Jakarta, Indonesia, 2013.

[74] KNKT, Aircraft Accident Investigation Report-Final Report No.KNKT/07.01/08.01.36-Boeing 737-4Q8 PK-KKW Makassar Strait, Sulawesi Republic of Indonesia 1 January 2007", National Transportation Safety Committee, Jakarta, Indonesia, 2008, https://knkt.dephub.go.id/knkt/ntsc_ aviation/aaic.htm.

[75] KNKT, Aircraft Accident Investigation Report-Final Report No.KNKT.09.08.21.04 De Haviland DHC6 Twin Otter. PKNVC. Near Ambisil/Okbibab, Papua. 2 August 2009, National Transportation Safety Committee, Jakarta, Indonesia, 2010, http://knkt.dephub.go.id/knkt/ntsc_aviation/aaic.htm.

[76] KNKT, Aircraft Accident Investigation Report-Final Report No.KNKT.08.01.02.04; Casa 212-200; PK-VSE; En-Route Tarakan-Long Apung-26 January 2008, National Transportation Safety Committee, Jakarta, Indonesia, 2010, http:// knkt.dephub.go.id/knkt/ntsc_aviation/aaic.htm.

[77] KNKT, Aircraft Accident Investigation Report-Final Report No.KNKT.11.11.25.04-C208B Cessna Grand Caravan; PKVVG; Bilogai Airstrip, Sugapa, Papua-26 November 2011”, National Transportation Safety Committee, Jakarta, Indonesia, 2013, http://knkt.dephub.go.id/knkt/ntsc_aviation/aaic. htm.
[78] KNKT, Aircraft Accident Investigation Report-Final Report No.KNKT.09.12.04.01; British Aerospace BAe 146-300; PKBRD; Wamena Airport, Papua-9 April 2009, National Transportation Safety Committee, Jakarta, Indonesia, 2009, http://knkt.dephub.go.id/knkt/ntsc_aviation/aaic.htm.

[79] KNKT, Aircraft Accident Investigation Report-Final Report No.KNKT.13.04.09.04-PT. Lion Mentari Airlines (Lion Air) Boeing 737-800; PK-LKS Ngurah Rai International Airport, Bali Republic of Indonesia 13 April 2013, National Transportation Safety Committee, Jakarta, Indonesia, 2013, http:// knkt.dephub.go.id/knkt/ntsc_aviation/aaic.htm.

[80] H. Kharoufah, J. Murray, G. Baxter, and G. Wild, "A review of human factors causations in commercial air transport accidents and incidents: from to 2000-2016," Progress in Aerospace Sciences, vol. 99, pp. 1-13, 2018.

[81] ICAO, Runway Safety Programme-Global Runway Safety Action Plan", ICAO, Montreal, Canada, 2017, https://www. icao.int/safety/RunwaySafety/Documents\%20and\% 20Toolkits/GRSAP_Final_Edition01_2017-11-27.pdf.

[82] D. Moriarty and S. Jarvis, "A systems perspective on the unstable approach in commercial aviation," Reliability Engineering \& System Safety, vol. 131, pp. 197-202, 2014.

[83] Y. Jiang, "Review on flight performance certification standard for wet and contaminated runway," Procedia Engineering, vol. 17, pp. 7-12, 2011.

[84] C. Cutler, "The FAA's braking action reports have changed, here's what you need to know," 2016, http://www. boldmethod.com/learn-to-fly/weather/faa-braking-action-re ports-have-changed-this-is-what-you-should-know/?fb_com ment_id=1425175300843897_1425902567437837\#f25bb46bf c6128.

[85] KNKT, Aircraft Accident Investigation Report-Final Report No.KNKT.11.02.04.04-Boeing 737-900ER; PK-LFI; Sultan Kasim Syarif II Airport, Pekanbaru, Riau-14 February 2011, National Transportation Safety Committee, Jakarta, Indonesia, 2013, http://knkt.dephub.go.id/knkt/ntsc_aviation/aaic. htm.

[86] KNKT, Aircraft Accident Investigation Report-Final Report No.KNKT.11.02.05.04-Boeing 737-900ER; PK-LHH; Sultan Kasim Syarif II Airport, Pekanbaru Riau-15 February 2011, NTFS Reports, Jakarta, Indonesia, 2013, http://knkt.dephub. go.id/knkt/ntsc_aviation/aaic.htm.

[87] IPI, Himbauan Keselamatan Penerbangan Tentang Approach and Landing, IPI, Vienna, Austria, 2016, http://ipi.or.id/himbauankeselamatan-penerbangan-tentang-approach-and-landing/.

[88] DGCA, “Airports," 2017.

[89] MoT, "Statistik perhubungan 2016," 2017, http://ppid.dephub. go.id/files/buku_statistik_perhubungan_jilid_1_2016.pdf.

[90] AirNav, "Striving best for improved safety and services-2015 annual report," 2015, http://e-office.airnavindonesia.co.id/ Annual\%20Report\%20Airnav\%202015.pdf.

[91] KNKT, Aircraft Runway Incursion Investigation Report-Final Report KNKT.09.10.16.04; DHC-6; PK-BRS, Soedjarwo Tjondronegoro Airport; Serui-Papua; 14 September 2009, National Transportation Safety Committee, Jakarta, Indonesia, 2014, http://knkt.dephub.go.id/knkt/ntsc_aviation/aaic. htm.

[92] KNKT, Aircraft Accident Investigation Report-KNKT.12.04.08.04-Pilatus Porter PC-6; PK-VVQ; Melak Area, East of Kalimantan-25 April 2012, National Transportation Safety Committee, Jakarta, Indonesia, 2013, http://knkt.dephub.go.id/knkt/ntsc_aviation/aaic.htm.

[93] J. A. Gomez-Ibanez, C. V. Oster Jr., and D. H. Pickrell, "Airline deregulation: what's behind the recent losses?" 
Journal of Policy Analysis and Management, vol. 3, no. 1, pp. 74-89, 1983.

[94] Indonesia, "Komite nasional keselamatan transportasi," in Peraturan Pemerintah Nomor 2 Tahun 2012, Indonesia, Ed., National Transportation Safety Committee, Jakarta, Indonesia, 2012.

[95] DGCA, Incident Database: 2007-2015 (Part 121 and 135), DGCA, Jakarta, Indonesia, 2017.

[96] I. A. Taib, A. S. McIntosh, C. Caponecchia, and M. T. Baysari, "A review of medical error taxonomies: a human factors perspective," Safety Science, vol. 49, no. 5, pp. 607-615, 2011.

[97] IATA, Runway Safety Accident Analysis Report 2010-2014, IATA, Montreal, Canada, 2015, https://www.iata.org/ contentassets/7a5cd514de9c4c63ba0a7ac21547477a/rsar-1st2015-final-version.pdf.

[98] IATA, IATA Controlled Flight into Terrain Accident Analysis Report-2008-2017 Data, https://www.iata.org/whatwedo/ safety/Documents/cfit-report.pdf, IATA, Montreal, Canada, 2018, https://www.iata.org/whatwedo/safety/Documents/cfitreport.pdf. 